\title{
Universiteit
}

Leiden

The Netherlands

\section{Glcp constitutes the major glucose uptake system of Streptomyces} coelicor A A3(2)

Wezel, G.P. van; Mahr, K.; König, M.; Traag, B.A.; Pimentel-Schmitt, E.F.; Willimek, A.;

Titgemeyer, F.

\section{Citation}

Wezel, G. P. van, Mahr, K., König, M., Traag, B. A., Pimentel-Schmitt, E. F., Willimek, A., \& Titgemeyer, F. (2005). Glcp constitutes the major glucose uptake system of Streptomyces coelicor A A3(2). Molecular Microbiology, 55(2), 624-636.

doi:10.1111/j.1365-2958.2004.04413.x

Version: Publisher's Version

License: $\quad$ Licensed under Article 25fa Copyright Act/Law (Amendment Taverne)

Downloaded from: https://hdl.handle.net/1887/3203733

Note: To cite this publication please use the final published version (if applicable). 


\section{GlcP constitutes the major glucose uptake system of Streptomyces coelicolor A3(2)}

Gilles P. van Wezel, ${ }^{2 \dagger}$ Kerstin Mahr, ${ }^{1 \dagger}$ Miriam König, ${ }^{1 \dagger}$ Bjørn A. Traag, ${ }^{2}$ Elisângela F. Pimentel-Schmitt, ${ }^{1}$ Andreas Willimek ${ }^{1}$ and Fritz Titgemeyer ${ }^{1 *}$ ${ }^{1}$ Lehrstuhl für Mikrobiologie, Friedrich-AlexanderUniversität Erlangen-Nürnberg, 91058 Erlangen, Germany.

${ }^{2}$ Department of Biochemistry, LIC, Leiden University, $P O$ BOX 9502, 2300 RA Leiden, the Netherlands

\section{Summary}

We provide a functional and regulatory analysis of $g l c P$, encoding the major glucose transporter of Streptomyces coelicolor A3(2). GIcP, a member of the Major Facilitator Superfamily (MFS) of bacterial and eucaryotic sugar permeases, was found to be encoded twice at two distinct loci, glcP1 and glcP2, located in the central core and in the variable right arm of the chromosome respectively. Heterologous expression of GIcP in Escherichia coli led to the full restoration of glucose fermentation to mutants lacking glucose transport activity. Biochemical analysis revealed an affinity constant in the low-micromolar range and substrate specificity for glucose and 2deoxyglucose. Deletion of $g / c P 1$ but not $g / c P 2$ led to a drastic reduction in growth on glucose reflected by the loss of glucose uptake. This correlated with transcriptional analyses, which showed that glcP1 transcription was strongly inducible by glucose, while glcP2 transcripts were barely detectable. In conclusion, GIcP, which is the first glucose permease from high G+C Gram-positive bacteria characterized at the molecular level, represents the major glucose uptake system in S. coelicolor A3(2) that is indispensable for the high growth rate on glucose. It is anticipated that the activity of GICP is linked to other glucosemediated phenomena such as carbon catabolite repression, morphogenesis and antibiotic production.

\section{Introduction}

Streptomycetes are Gram-positive soil bacteria that are

Accepted 27 September, 2004. *For correspondence. E-mail ftitgem @ biologie.uni-erlangen.de; Tel. (+49) 9131852 8084; Fax (+49) $91318528082 .{ }^{\dagger}$ These authors contributed equally to this work. widely used as producers of antibiotics and many other beneficial compounds (Bibb, 1996; Baltz, 1998). In nature, they contribute as soil-dwelling bacteria substantially to the degradation of dead plant and animal material by their ability to utilize a wide variety of complex polysaccharides, including cellulose, xylan and chitin (Hodgson, 2000). This is achieved by the action of exoenzymes that break down the polysaccharides to mono- and disaccharides, which are internalized by specific carbohydrate uptake systems. More than 50 carbohydrate permeases were identified on the Streptomyces coelicolor A3(2) genome (Bertram et al., 2004). A few have been described at the molecular level in various streptomycetes. Cellobiose/cellotriose, maltose, trehalose and xylobiose are taken up via ATP-driven $A B C$ transport systems, while fructose and $\mathrm{N}$-acetylglucosamine are transported by the phosphotransferase system (PTS) (Hurtubise et al., 1995; Schlösser and Schrempf, 1996; Schlösser et al., 1997; Schlösser, 2000; Wang et al., 2002; Nothaft et al., 2003a,b).

The molecular nature of the glucose uptake system of streptomycetes, which is considered the most favourable nutrient in these organisms, is unknown. This lack of information is surprising as many glucose-mediated processes, including antibiotic production, morphogenesis and carbon catabolite repression (CCR), are under intensive investigation (Pope et al., 1996; van Wezel et al., 1997; Escalante et al., 1999; Ueda et al., 2000; Kim et al., 2001; Seo et al., 2002). A number of glucose-negative strains have been isolated as mutants resistant to the toxic analogon 2-deoxyglucose (Hodgson, 1982; Kwakman and Postma, 1994). As the mutations all map to the gene encoding glucose kinase and none to a transporterencoding gene, it became obvious that more than one glucose permease must exist. The presence of a constitutive, low-affinity transport system has been reported for S. coelicolor and Streptomyces violaceoruber with affinity constants of $6.1 \mathrm{mM}$ and $1 \mathrm{mM}$ (Sabater and Asensio, 1973; Hodgson, 1982). In the course of a study on ABCtype disaccharide transporters, it was noted that Streptomyces lividans has a high- and low-affinity glucose uptake activity with affinity constants of $120 \mu \mathrm{M}$ and $6.2 \mathrm{mM}$ (Hurtubise et al., 1995). The isolation of a glucose-utilization mutant from the naturally glucose-negative Streptomyces clavuligerus wild-type strain revealed a glucose permease with a broader substrate specificity that is energized by the proton motive force (Garcia-Dominguez et al., 1989). 
None of these permeases have been characterized at the molecular level.

In search for a possible glucose permease, we previously detected GIcP in the genome of $S$. coelicolor A3(2), a permease of the major facilitator superfamily (MFS) that shares $51 \%$ protein identity to a glucose permease of Synechocystis (Zhang et al., 1989; Bertram et al., 2004). Interestingly, GlcP is encoded twice on the chromosome by the genes $g / c P 1$ (SCO5578) and glcP2 (SCO7153), which differ only in one base pair giving rise to a silent mutation and thus produce identical gene products. In this communication, we provide a biochemical analysis of GlcP. We further describe its in vivo role and transcriptional regulation through mutational dissection of $g / c P 1$ and $g l c P 2$, which shows that GlcP is the major glucose transporter in S. coelicolor A3(2) that is indispensable for maintaining a high growth rate on glucose.

\section{Results}

To characterize glucose internalization in $S$. coelicolor A3(2), we determined the kinetic parameters and the inducibility of glucose uptake. Glucose transport assays were conducted with strain M145 grown in mineral medium supplemented with glycerol or glycerol plus glucose. As depicted in Fig. 1A, uptake of glucose was strongly induced in the presence of glucose. Measurement of the initial uptake rates at various glucose concentrations revealed an overall glucose uptake activity into mycelia with an apparent $K_{\mathrm{m}}$ of $137 \pm 16.5 \mu \mathrm{M}$ and with a $V_{\max }$ of $22 \pm 2.4 \mathrm{nmol}$ per minute per mg dry weight (Fig. 1B).

\section{Functionality of GICP resolved by heterologous expression}

In the course of an in silico screen for carbohydrate uptake systems present in the genome of $S$. coelicolor A3(2), we have recently predicted that GIcP may function as a glucose permease (Bertram et al., 2004). GlcP is a member of the MFS, which comprises $\mathrm{H}^{+}$/symporters and facilitator proteins (Pao et al., 1998; Bertram et al., 2004). GlcP is encoded by two duplicated genes, where one is situated in the constant region of the chromosome (SCO5578, $g / c P 1)$ and one is found in the variable right arm of the chromosome (SCO7153, glcP2) (Fig. 2). Both genes encode identical gene products of 472 amino acids. The duplicated area includes 36 bp of upstream region containing a $16 \mathrm{nt}$ palindrome sequence that could serve as a transcription factor binding site (Fig. 2). The homology ends exactly with the stop codon, and the genes are followed by non-related stem loop structures forming potential transcriptional termination signals. The deduced sequence exhibits $51 \%, 32 \%$ and around $30 \%$ overall identity to the glucose transporters GIcP of Synechocystis PCC6803 and Glf of Zymomonas mobilis, and to mammalian glucose permeases, respectively, and between $28 \%$ and $37 \%$ amino acid identity to bacterial uptake systems specific for arabinose, galactose or xylose (Zhang et al., 1989; Weisser et al., 1995; Pao et al., 1998).

To examine the function of GlcP, we expressed the gene in Escherichia coli. The glcP-coding region was cloned by polymerase chain reaction (PCR) from the $S$. coelicolor A3(2) M145 genome, and inserted into vector pSU2718 behind the lac $Z$ promoter, yielding pFT76. The glucosenegative E. coli strains LR2-175 and LM1 that lack detectable glucose transport activity were transformed with pFT76. The transformants were streaked onto MacConkey agar plates supplemented with $50 \mathrm{mM}$ glucose (Fig. 3A). LR2-175(pFT76) and LM1(pFT76) formed red colonies because of the fermentation of glucose, while non-glucose-fermenting white colonies were observed when the strains carried the control plasmid pSU2718. Subsequent glucose uptake measurements showed that glucose was efficiently internalized in E. coli strain LR2175(pFT76), while no transport was observed for transformants harbouring the control plasmid without $\mathrm{glcP}$ (Fig. 3B). Hence, heterologous expression of $g l c P$ in $E$. coli identified GlcP as a glucose permease.

The function of $S$. coelicolor GlcP was studied in more detail. Therefore, we took advantage of heterologously produced GlcP in E. coli LR2-175(pFT76), which
A

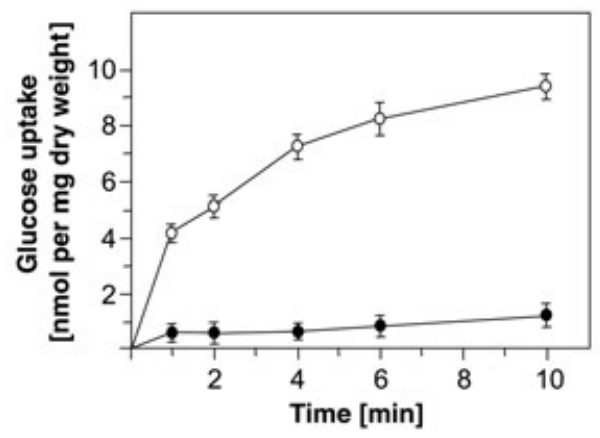

B

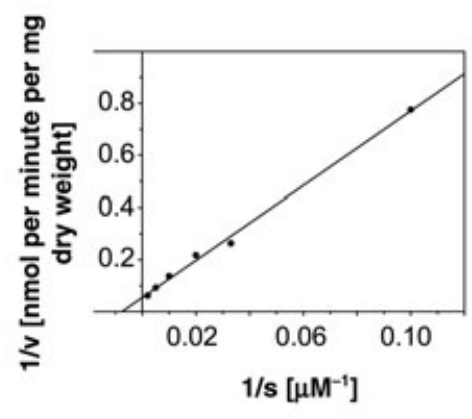

Fig. 1. Glucose transport in S. coelicolor A3(2). A. Glucose uptake as a function of time. Mycelia of $S$. coelicolor A3(2) M145 were grown in mineral medium containing $0.1 \%$ casamino acids and supplemented with either $50 \mathrm{mM}$ glycerol (non-inducing growth conditions; $\bullet$ ) or $50 \mathrm{mM}$ glycerol plus $50 \mathrm{mM}$ glucose (inducing growth conditions; $\bigcirc$ ). Standard deviations of triplicate data points are shown by error bars. B. Lineweaver-Burk plot of glucose uptake rates of $S$. coelicolor A3(2) M145 as a function of glucose concentration. $K_{\mathrm{m}}$ and $V_{\max }$ were calculated from three experiments. 

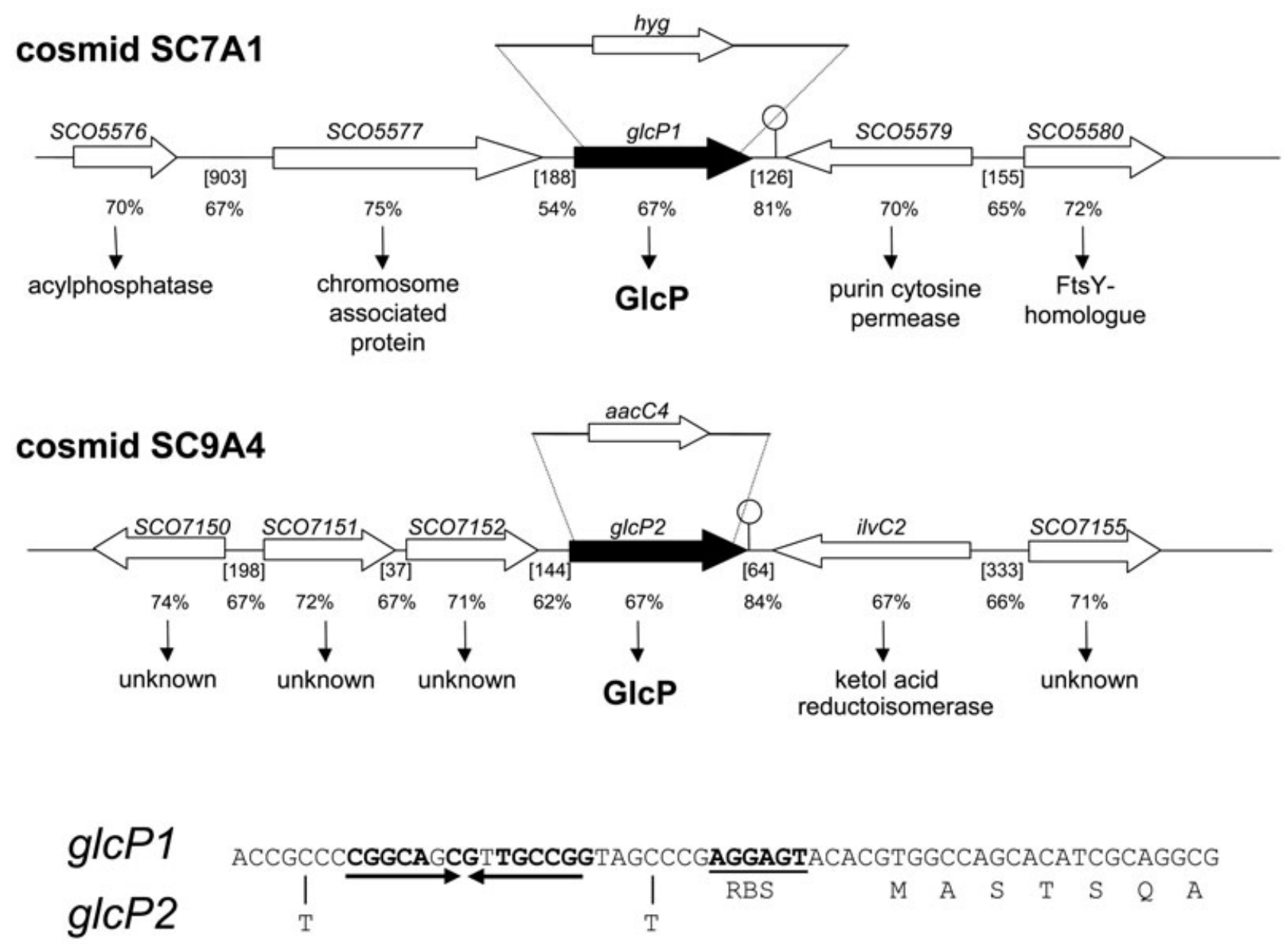

Fig. 2. Genetic map of the glcP1 and $g l c P 2$ loci. Unknown genes are designated with the respective SCO number above and the names of predicted proteins below the genes. The lengths of the intergenic regions are indicated in brackets (in nt). The $\mathrm{G}+\mathrm{C}$ content of coding and intergenic regions is expressed in percentages. Two putative transcription termination sites are marked as stem loops (CCGCCGCCCCGCCCG GTCGCATTCCGGGCGGGGCGGCGG, 62 nt downstream of glcP1; GCAGGCCGGTGGGCGCGCCGCCGTGGCGCGCCCACCGGCCTGC $14 \mathrm{nt}$ downstream of $\mathrm{g} / \mathrm{cP} 2$ ). The relative extensions of $\mathrm{glcP}$ deletions and the inserted antibiotic resistance gene cassettes are given. The conserved upstream regions of $36 \mathrm{nt}$ including a $16 \mathrm{nt}$ palindromic sequence is shown at the bottom.

was free of any background activity. We measured a $K_{\mathrm{m}}$

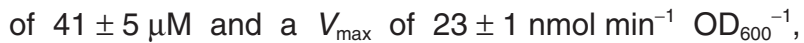
which means that GlcP is a high-affinity transport system (Fig. 3C). The presence of the ionophores carbonyl cyanid-m-chlorophenyl-hydrazone (CCCP) and dinitrophenol (DNP) that both destroy the membrane potential resulted in residual glucose transport activity of $5 \%$ and $7 \%$, respectively, whereas the ATP-formation inhibitor $N, N$ 'dicyclohexylcarbodiimide (DCCD) had no significant influence (Fig. 3D). Concerning the substrate specificity, it was reported that the homologues from Synechocystis and Z. mobilis transport fructose (Zhang et al., 1989; Parker et al., 1995; Weisser et al., 1995). However, strain LR2-175(pFT76), which lacks a functional fructose permease, exhibited no detectable fructose uptake (data not shown). Subsequent uptake competition experiments confirmed this and showed further that 2deoxyglucose was readily recognized by GlcP, while this was not the case for methyl $\alpha$-D-glucopyranoside (Fig. 3E).

\section{Mutational analysis of glcP1 and glcP2}

After identification of GlcP as a glucose-specific permease, we analysed its role in glucose transport in $S$. coelicolor A3(2). Two single and a double mutant were constructed that carried a deletion in glcP1 (BAP17), glcP2 (BAP18), or in both genes (BAP19) respectively. All mutants sporulated normally on mineral and complex media, as judged by phase contrast microscopy. As the genes located downstream of $g / c P 1$ and glcP2 are oriented in the opposite orientation (Fig. 2), polar effects resulting from the insertion of a resistance cassette in glcP1 or glcP2 were highly unlikely.

To assess the ability of the mutants to utilize glucose as sole carbon source, we compared the growth curves 
A

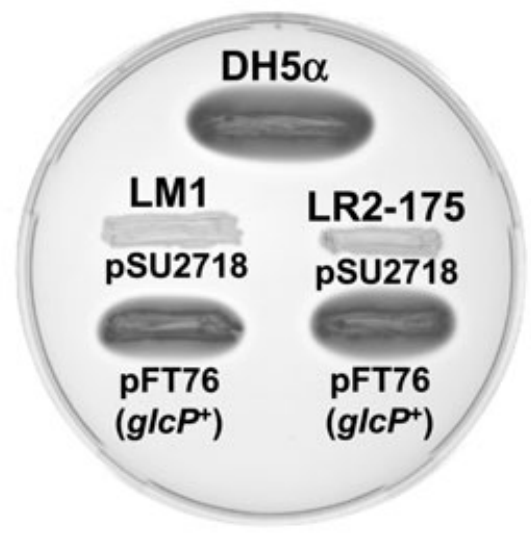

B

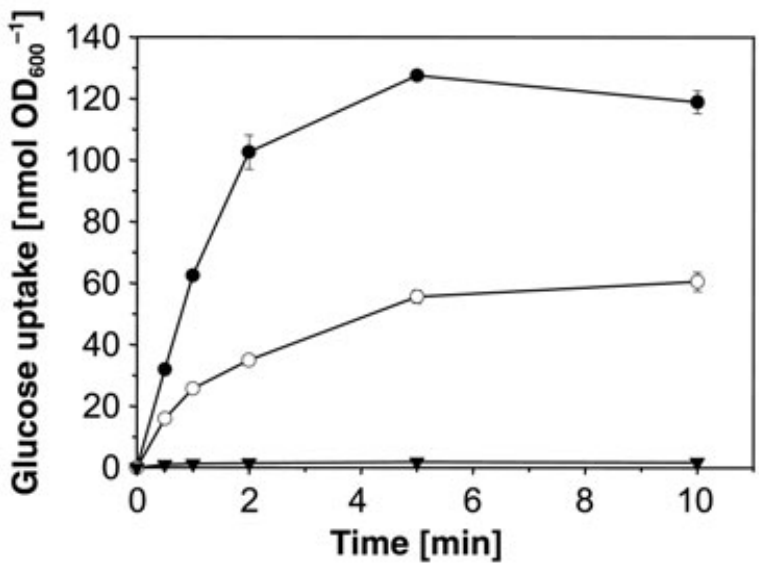

C

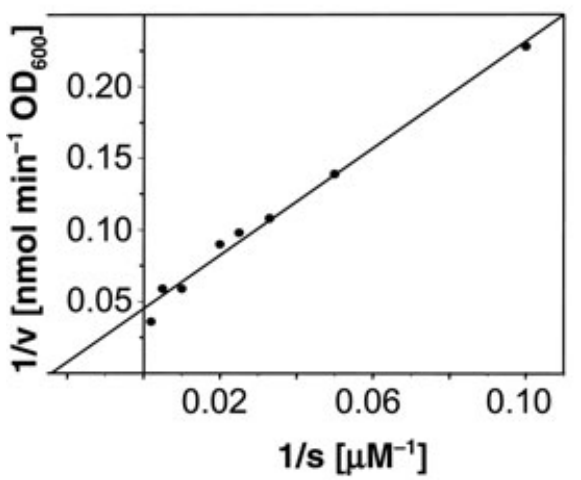

D

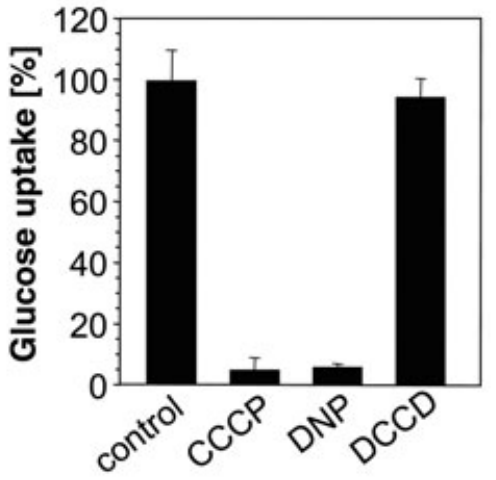

E

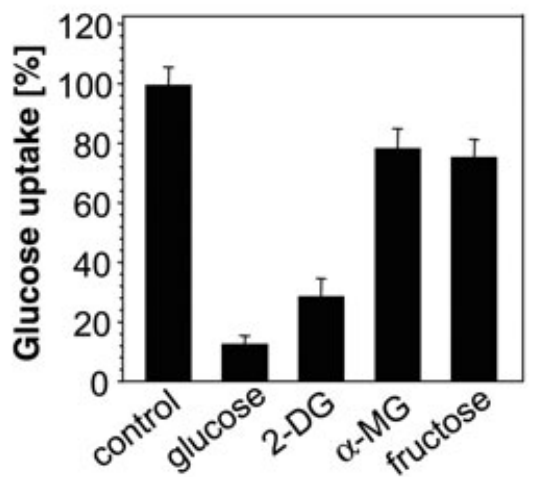

Fig. 3. Identification of the glucose transporter GlcP of $S$. coelicolor A3(2).

A. Complementation of the glucose-negative phenotype in E. coli. DH5 $\alpha$ (pSU2718) (positive control), LM1(pSU2718) (negative control), LM1(pFT76 glcP2'), LR2-175(pSU2718) (negative control) and LR2-175(pFT76 glcP2') were streaked on a MacConkey agar base plate supplemented with $50 \mathrm{mM}$ glucose. Pigmented red colonies (dark grey) indicate the fermentation of glucose, whereas white colonies (light grey) reflect a deficiency in glucose fermentation.

B. Time-dependent uptake of $\left[{ }^{14} \mathrm{C}\right]$-glucose of E. coli DH5 $\alpha(\mathrm{pSU} 2718)(\mathbf{O}$; positive control), LR2-175(pSU2718) ( $\mathbf{\nabla}$; negative control) and LR2175(pFT76 $\left.g / c P^{+}\right)(\bigcirc)$.

C. Lineweaver-Burk plot of glucose uptake rates of LR2-175(pFT76) as a function of glucose concentration. $\mathrm{K}_{\mathrm{m}}$ and $\mathrm{V}_{\mathrm{max}}$ were determined from three experiments.

D. Transport inhibition assay using ionophores CCCP $(50 \mu \mathrm{M})$ and DNP $(1 \mathrm{mM})$, and the ATP-formation inhibitor DCCD (0.5 mM). Transport activity without effectors was set to $100 \%$ (control).

E. Glucose uptake competition assay using a 100-fold excess of non-radioactive sugars (10 mM). Transport activity without additional sugar was set to $100 \%$ (control).

Standard deviations of triplicate data points are shown by error bars. Very similar results were obtained from three independent experiments. 2DG, 2-deoxyglucose; $\alpha \mathrm{MG}$, methyl $\alpha$-D-glucopyranoside.

with the parental strain M145. For this purpose, $500 \mathrm{ml}$ NMMP cultures with glucose were inoculated with precultures of the respective strains at an $O_{550}$ of 0.1 and allowed to grow at $30^{\circ} \mathrm{C}$ (Fig. 4A). While deletion of glcP2 in BAP18 did not affect growth on glucose, the glcP1 mutant BAP17 and the double mutant BAP19 showed clearly reduced growth rates. Monitoring of glucose in the medium showed that the parental M145 and BAP18 immediately utilized glucose. NMMP cultures contained $0.2 \%$ casamino acids in addition to glucose, which is sufficient to support initial growth up to $\mathrm{OD}_{550}$ of 0.3 (van
Wezel et al., 1997). Glucose consumption in the two strains lacking $g / c P 1$ started significantly later, corresponding to a time point where the casamino acids became limited (approximately after 10-12 h). A similar experiment with mannitol as the sole carbon source revealed no noticeable difference in growth rates and biomass formation between M145 and the three mutants, showing that the differences indeed resulted from their inability to grow properly on glucose, and not by any other defect (data not shown).

The growth analysis corresponded with the ability of the 
A

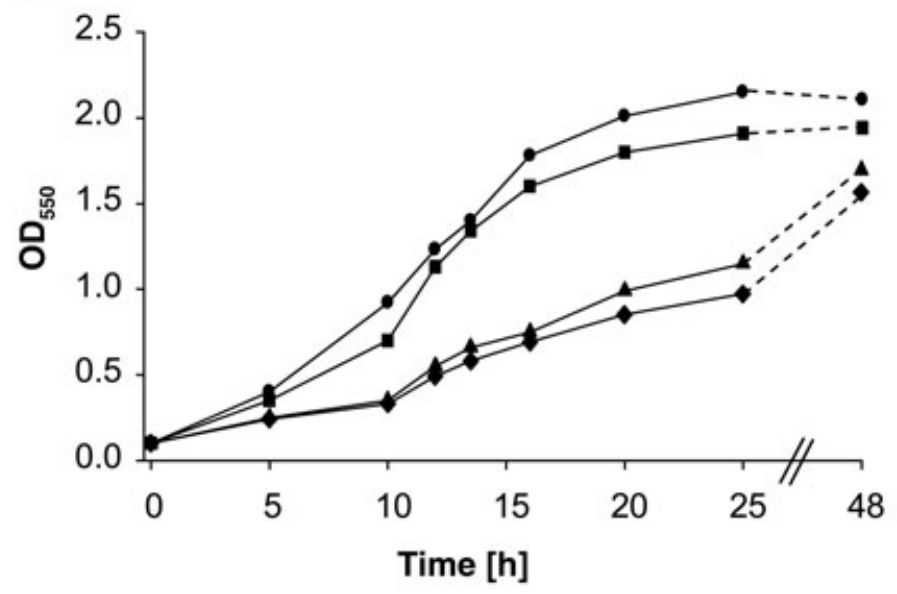

C

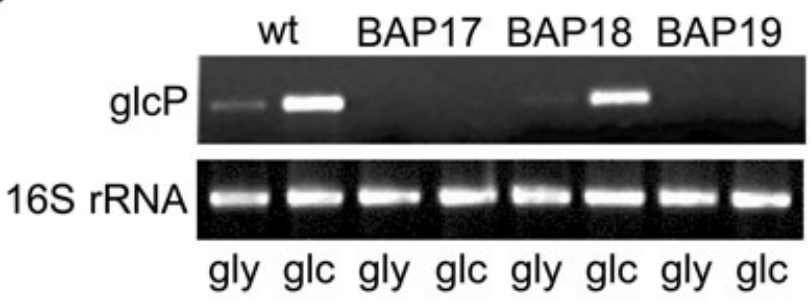

B

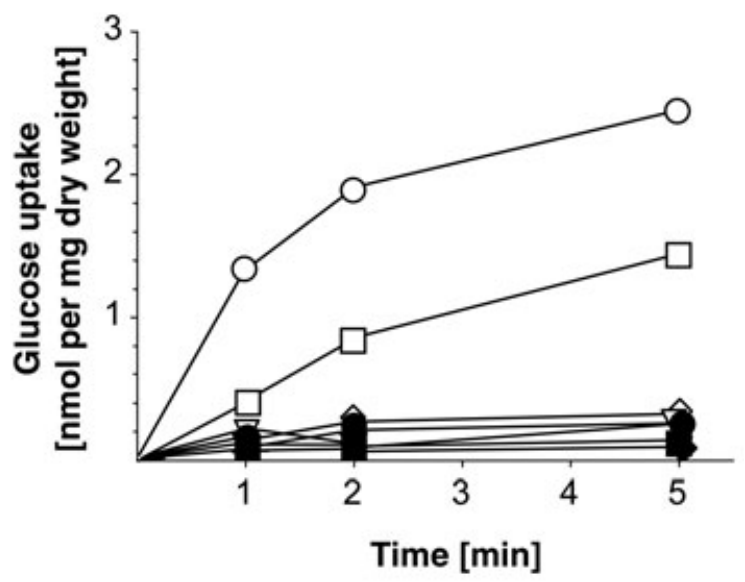

D

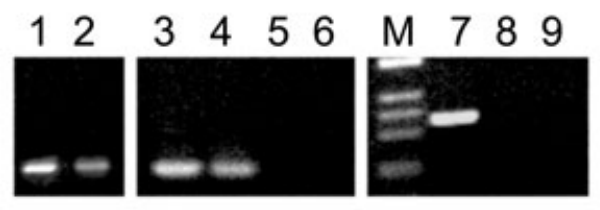

Fig. 4. Growth and expression of $g l c P 1$ and $g l c P 2$.

A. Growth of $S$. coelicolor A3(2) M145 (-) and glcP mutants BAP17 ( $\Delta g / c P 1 ; \mathbf{\Delta})$, BAP18 $(\Delta g / c P 2 ; \mathbf{\square})$ and BAP19 ( $\Delta g / c P 1 \Delta g l c P 2 ; \bullet)$ on NMMP plus $50 \mathrm{mM}$ glucose.

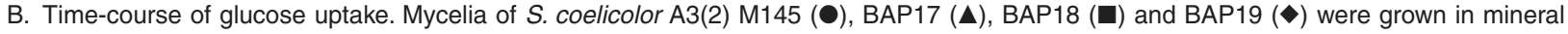
medium containing $0.1 \%$ casamino acids and $50 \mathrm{mM}$ glycerol (closed symbols) or $50 \mathrm{mM}$ glycerol plus $50 \mathrm{mM}$ glucose (open symbols). Data were reproduced by three experiments.

C. RT-PCR of glcP transcripts of S. coelicolor A3(2) M145 and glcP mutants. A $1 \%$ agarose gel shows RT-PCR amplification products of glcP1/ 2-mRNA after cycle 24. Total RNA was prepared from cultures grown on mineral medium supplemented with $0.1 \%$ casamino acids and 50 mM glycerol in the presence (glc) and absence of $50 \mathrm{mM}$ glucose (gly).

D. Identification of $g / c P 2$ and anti-sense transcripts by RT-PCR. Left: identification of glcP2 transcripts in RNA from S. coelicolor A3(2) M145, using extended RT-PCR (35 cycles) and allele-specific primers. Lane 1: saturated signal of glcP1 (primers GlcP1-RTF + GlcP-RTR); lane 2: weaker signal for glcP2 (primers GlcP2-RTF + GlcP-RTR). Middle: RT-PCR using 25 cycles shows glcP1 transcripts present in RNA from S. coelicolor A3(2) M145 (lane 3) and from glcP2 mutant BAP18 (lane 4). Lanes 5 and 6 present controls of lanes 3 and 4 , respectively, showing the absence of RT-PCR product when the cDNA synthesis (RT) step was omitted. Note that glcP1 transcripts are less abundant in the glcP2 mutant (probably because of the anti-sense transcript visualized in lane 7). Right: identification of anti-sense transcripts in the glcP2 mutant. Lane 7: anti-sense RNA product generated by RT-PCR from RNA from BAP18 (primers apra-up + GIcP2-RTF); lane 8: same as lane 7, but without RT step (control to confirm the absence of genomic DNA); lane 9: same as lane 7, but with RNA isolated from M145 instead of the glcP2 mutant. To ascertain that only anti-sense transcripts could be identified, the cDNA synthesis step was carried out in the presence of only the glcP2specific (forward) primer. M: DNA size marker (from top to bottom: 517, 396, 344, 298, and double band of $220 / 201$ bp).

mutants to incorporate glucose, which was substantial in the presence of an intact $g / c P 1$ gene and barely detectable in strains carrying a glcP1 deletion (Fig. 4B). Expectedly, glucose transport was negligibly low in the glcP1 mutant. Thus, we conclude that $g l c P 1$ alone accounts for maintenance of the high growth rate on glucose, which is in agreement with the growth analysis presented above. Surprisingly, glucose transport in the glcP2 mutant was only about $50-60 \%$ of the wild-type level, suggesting that perhaps $g / c P 1$ is expressed at a lower level in the $\triangle g / c P 2$ background as compared with the parental M145. This was confirmed by our reverse transcription polymerase chain reaction (RT-PCR) data, and most probably results from the production of an anti-sense transcript from the apramycin resistance cassette inside the $g / c P 2$ gene (see below).

\section{Transcription analysis by RT-PCR}

Total $g / c P(g / c P 1+g l c P 2)$ transcript levels in M145 and its $g / c P$ mutant derivatives were quantitatively determined by semi-real-time RT-PCR, using primers GICP-RT1 and GlcP-RT2 that hybridized perfectly to both genes. As can be inferred from Fig. $4 \mathrm{C}$, glcP transcripts were readily 
detectable in glucose-grown M145 (total glcP-mRNA) and in the glcP2 mutant BAP18 (allowing the detection of only glcP1-mRNA), while only marginal glcP expression was observed in glycerol-grown cultures. Under these conditions, we failed to detect transcripts in the glcP1 mutant, or - expectedly - in the double mutant BAP19.

Similar experiments were also carried out using genespecific primers, to allow discrimination between glcP1and $g / c P 2$-derived mRNA. Therefore, we used oligonucleotides GlcP1-RTF and GlcP2-RTF as forward primers, which hybridized specifically to the region around nt position -60 relative to the start of $g / C P 1$ or $g / c P 2$ respectively. The reverse primer (GlcP-RTR) was chosen around nt position +130 , so as to recognize both genes. Considering the expected difference in mRNA levels of $g / c P 1$ - and glcP2-derived transcripts, we performed semi-real-time PCR, analysing samples at three-cycle intervals. After the maximal 35 amplification cycles, a very strong and saturated signal was observed for $g l c P 1$, and a weak band for glcP2 (Fig. 4D, lanes 1 and 2). The intensity of the glcP2derived band obtained after 35 cycles corresponded to the band obtained from glcP1-derived transcripts after only 21 cycles (data not shown), illustrating the large difference in expression level (see also below). A control experiment without reverse transcriptase did not show any PCR product (lanes 5 and 6), showing that the bands were transcript specific.

Interestingly, $g / c P 1$-derived transcripts were significantly lower in the glcP2 mutant as compared with M145 (Fig. $4 \mathrm{C}$ and D). We anticipated the possibility that an antisense transcript would be produced in the glcP2 mutant, which would hybridize perfectly over a stretch of $64 \mathrm{nt}$ to nt positions $-36 /+28$ of the gICP1-mRNA, and would therefore interfere with $g / c P 1$ expression (see also Fig. 2). To test this, we performed an RT-PCR experiment using primers GIcP2-RTF and apra-up, which were specific for the $g / c P 2$ upstream region and the start of the apramycin resistance cassette respectively. CDNA was produced in the presence of only GlcP2-RTF, reverse transcriptase was inactivated, after which primer apra-up was added and the PCR amplification was performed. In this way, only anti-sense transcripts could be amplified. As can be derived from Fig. 4D (lane 7), a clear and strong band was produced, showing that indeed significant amounts of anti-sense transcripts were present in the g/cP2 mutant. Control experiments using the same RNA without reverse transcriptase (DNA control) or on RNA from the glcP1 mutant did not result in any product (Fig. 4D, lanes 8 and 9 respectively).

\section{Transcription of glcP1 is induced by glucose}

The promoter activities were analysed in vivo in a complementary experiment by taking advantage of the redD promoter probe system (van Wezel et al., 2000). For this purpose, 242 bp DNA fragments containing either the glcP1 or the glcP2 upstream region (nt positions $-192 /+49$ relative to the start of the respective genes) were placed in front of the promoterless redD gene. The resulting constructs plJ2587-glcP1p and plJ2587-glcP2p were introduced in the non-pigmented indicator strain $S$. coelicolor A3(2) M512, and grown on R2YE plates for 6 days (Supplementary material, Fig. S1). Production of the red-pigmented undecylprodigiosin (Red) was strongly stimulated by the presence of plJ2587-glcP1p in M512, while no stimulation of Red production was observed in M512(plJ2587-glcP2p). Hence, the data suggest that only glcP1 was transcribed.

High resolution transcript analysis was used to study transcription of $g / c P 1$ and $g / c P 2$ in more detail. Nuclease S1 mapping experiments using probe GP1 revealed a single nuclease-protected band of $134 \mathrm{nt}$, corresponding to the $g / c P 1$ transcript, with the A residue at nt position -86 (relative to the start of the gene) as the most likely transcriptional start site (Fig. 5A). Appropriate consensus -10 (TAGTCT) and -35 (TTGACT) sequences were found at the expected positions (Supplementary material, Fig. S1). These sequences corresponded well to the consensus sequences recognized by the $0^{70}$-type major sigma factor HrdB of S. coelicolor (Strohl, 1992). In the reverse experiment, where we used a similar probe (called GP2), now designed to hybridize to glcP2 mRNA, we could only detect a very faint band on the gel after prolonged exposure on the phosphorimager plate, again showing the very low transcriptional activity of the glcP2 promoter (data not shown).

The onset of glcP1 transcription was followed for $4 \mathrm{~h}$ after mycelia of the exponential phase had been transferred from complex medium to mineral medium. The inducibility of $g / c P 1$ by glucose is underlined by the observation that maximal transcript levels were observed within $15 \mathrm{~min}$ after transfer to glucose-containing mineral medium (NMMP without casamino acids), with transcript levels decreasing significantly in time points later than $1 \mathrm{~h}$ (Fig. 4D). In contrast to in glucose-exposed cultures, glcP1 transcription was only slightly elevated in mannitolexposed cultures, and for a much shorter time. These data thus demonstrate the immediate expression of $g / c P 1$ in response to glucose.

\section{Discussion}

Glucose is widely used in Streptomyces research as a preferred nutrient to study carbon source-dependent phenomena. Its utilization triggers CCR and delays the onset of antibiotic production and development (Angell et al., 1994; Kwakman and Postma, 1994; Bibb, 1996; Chater, 1998; Gagnat et al., 1999). Generally, transport and CCR 
A

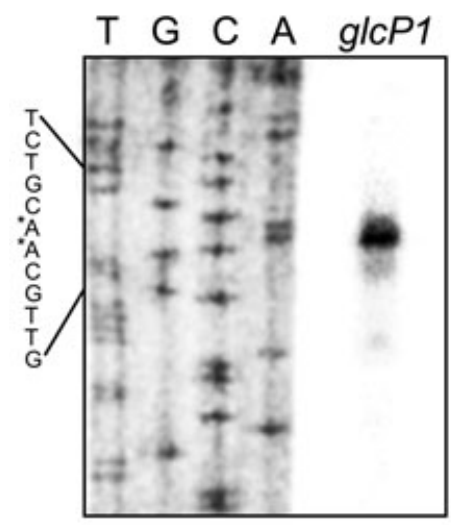

B

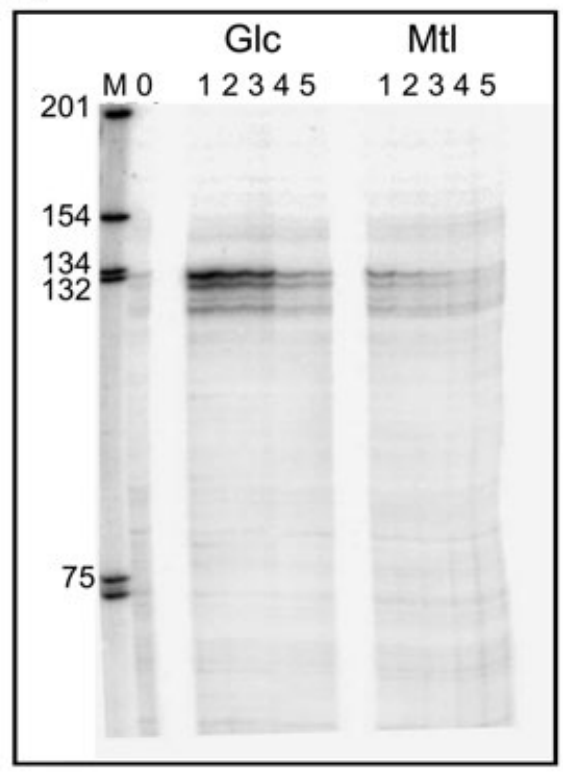

Fig. 5. Transcriptional analysis of $g / c P$. A. Mapping of the $g / c P 1$ transcriptional start site. TGCA, DNA sequence ladder; glcP1, transcript derived from the $g / c P 1$ promoter. The same sample was used as described in Fig. 5B (lane 1, Glc). The most likely transcriptional start sites are indicated by asterisks next to the DNA sequence.

B. Onset of glcP1 transcription in S. coelicolor A3(2) M145. Mycelium from an exponentially growing liquid-grown TSB culture was harvested at $\mathrm{OD}_{550}=0.6$ and resuspended in NMMP with either glucose (Glc) or mannitol (Mtl) as the sole carbon source. RNA was isolated at various time points and analysed by nuclease S1 mapping. Lanes: M, molecular size marker ( $\mathrm{nt}$; ${ }^{32} \mathrm{P}$-radiolabelled $1 \mathrm{~kb}$ ladder, Gibco BRL); 0, RNA isolated from TSB $(\mathrm{t}=0 \mathrm{~min}) ; 1-5$, samples corresponding to RNA isolated 15, 30, 60, 120 and 240 min after transfer from TSB to mineral medium respectively. The length of the full-sized transcript (approximately $134 \mathrm{nt}$ ) corresponds very well to the transcription start site predicted from the DNA sequence. are closely linked, and to obtain more insight into the glucose-related phenomena, identification of the highaffinity transporter is a prerequisite (Brückner and Titgemeyer, 2002). Furthermore, several industrial streptomycetes, including the clavulanic acid producer $S$. clavuligerus, are not able to utilize glucose, and this most probably results from defective transport (GarciaDominguez et al., 1989). Thus, a better insight into the uptake of glucose by actinomycetes is important from both a fundamental and a biotechnological perspective. We here show that the glucose permease GlcP is a highaffinity glucose transporter that is indispensable to maintain the high growth rate on this carbon source, and thus constitutes the major glucose transporter. As a particular feature, we found that the gene for GlcP is duplicated, resulting in identical gene products.

Biochemical characterization of heterologously expressed GlcP suggests that the permease constitutes a $\mathrm{H}^{+}$/symporter. A hydrophobicity analysis revealed a predicted topology of GlcP of six plus six transmembrane segments interrupted by a large cytoplasmic loop (Supplementary material, Fig. S2). These data are in accordance with the classification of GIcP as a member of the MFS, which includes either proton symporters or facilitator proteins of such a topology (Pao et al., 1998). Beside glucose, GlcP efficiently recognized 2-deoxyglucose, but not methyl $\alpha$-glucoside, a feature also demonstrated for the homologous chicken liver glucose transporter Ch-GT2 (Wang et al., 1994). Fructose is not transported by GlcP, which distinguishes it from the bacterial glucose permeases from Synechocystis and Z. mobilis that represent the closest homologues (Zhang et al., 1989; Weisser et al., 1995). The functional expression of $g l c P$ in $E$. coli is to our knowledge the first demonstration of the production of a streptomycete membrane protein in this host.

In the bacterial world the transport of glucose is, with very few exceptions, mediated by glucose-specific PTSs that couple transport to phosphorylation (Postma et al., 1993). Previous studies indicated that $S$. coelicolor and other Streptomyces species do not have a glucose PTS (Titgemeyer et al., 1995; Parche et al., 2000). It was further assumed that $S$. coelicolor should have at least two transporters for glucose (see Introduction). Our data corroborate this assumption. We conclude that GlcP represents an efficient glucose uptake system. Elimination of GlcP leads to a significant reduction of the glucose growth rate and to loss of high-affinity uptake. As the GlcP-negative double mutant BAP19 was able to utilize glucose although at a low rate - there should be at least one lowaffinity system present. We failed to detect such a system in our transport assays, in which we measured so-called 'true uptake' that occurs in the range of seconds using sugar concentrations up to $1 \mathrm{mM}$. A constitutive lowaffinity glucose transport activity $\left(K_{\mathrm{m}}\right.$ of $\left.6.1 \mathrm{mM}\right)$ has been described earlier (Hodgson, 1982). The assay conditions used in this work and the late time points taken (10$60 \mathrm{~min}$ ) were directed at monitoring slow uptake using millimolar glucose concentrations, and hence the highaffinity uptake system was not observed. Hurtubise et al. (1995) reported the presence of both a high- $\left(K_{\mathrm{m}}\right.$ of $120 \mu \mathrm{M})$ and a low-affinity $\left(K_{\mathrm{m}}\right.$ of $\left.6.2 \mathrm{mM}\right)$ glucose transport activity in $S$. lividans. The $K_{m}$ of the high-affinity transport activity corresponded very well to what we have measured in $S$. coelicolor $\mathrm{A} 3(2)$ mycelia $\left(K_{\mathrm{m}}\right.$ of $\left.137 \mu \mathrm{M}\right)$. 
These data are further consistent with our detection of a functional, almost identical glcP gene from S. lividans TK24 (Accession No. AF352022) that has four silent base substitutions compared with $S$. coelicolor A3(2) glcP1. However, the determined $K_{\mathrm{m}}$ of $41 \mu \mathrm{M}$ for GlcP, when expressed in an $E$. coli mutant that is free of intrinsic glucose transport activity, was somewhat lower than the high-affinity $K_{m}$ derived from $S$. coelicolor A3(2) mycelia. This difference might be explained by the possibility that the activity of GIcP differs slightly when expressed in the two different bacterial species. As for the low-affinity uptake, we propose that at least one permease perhaps with another sugar specificity may account for residual glucose incorporation. This is the case in E. coli that also uses the mannose- and galactose-specific permease for glucose import (Postma et al., 1993). Candidate genes have been recently described (Bertram et al., 2004). One of those could be encoded by the galactose permease gene galP that exhibits significant similarity to the glucose permease of Vibrio parahaemolyticus (Sarker et al., 1996).

The glucose transport experiment depicted in Fig. 4B showed an interesting feature that could not be explained easily from the GlcP activity alone. Expectedly, strains carrying a glcP1 deletion showed only very weak transport. However, we did not anticipate that deletion of the almost silent $g / c P 2$ should reproducibly result in a 40-50\% reduction of overall GIcP transport activity, suggesting that glcP1 is expressed at a lower level in the glcP2 mutant. The existence of a second efficient transport system can be ruled out, as the $g / c P 1 / g l c P 2$ double mutant failed to transport glucose at an appreciable rate. This is further consistent with the observed reduced growth rates on glucose in strains lacking glcP1. Our RT-PCR data showed that indeed $g / c P 1$ transcript levels were significantly reduced in the glcP2 mutant. Intriguingly, we found that the most likely explanation for this apparent inconsistency was RNA interference, as we demonstrated that the apramycin resistance cassette inside glcP2 generated high levels of an anti-sense transcript. This anti-sense transcript is complementary to $g / c P 1$ transcripts over a stretch of $64 \mathrm{nt}$, allowing possible hybridization to the $-36 /$ +28 section of the sense transcript. Obviously, this will not only interfere with $g / c P 1$ transcription, but certainly also with its efficient translation, as the ribosome binding site would be blocked for binding to the $3^{\prime}$ end of the $16 \mathrm{~S}$ rRNA.

Transcriptional analysis revealed that the expression of glcP1 was strongly inducible by glucose. Almost no expression of $g / c P 2$ was detectable under the conditions tested, suggesting the latter is less important or plays a role under different culturing conditions. The first possibility is supported by the finding that Streptomyces avermitilis harbours only one glcP allele (SAV2657; annotated as a putative arabinose permease; $89 \%$ protein identity) (Ikeda et al., 2003). Inspection of the surrounding genes clearly shows that this is a homologue of glcP1 of $S$. coelicolor A3(2). Moreover, glcP2 is situated within the right variable arm of the $S$. coelicolor $A 3(2)$ genome, a region of genetic instability (Bentley et al., 2002). The possibility that $g l c P 2$ is an active gene is supported by the facts that: (i) weak transcription of glcP2 was observed, (ii) it encodes a functional product, and identical to GIcP1, suggesting evolutionary pressure or perhaps a very recent duplication event, and (iii) the $g / c P 1$ and $g / c P 2$ genes are preceded by the same $36 \mathrm{bp}$ inverted repeat, which comprises the ribosome binding site and constitutes a possible binding site for a transcriptional regulator.

Beside the presence of $g l c P$ homologues in several Streptomyces species (89-100\% protein identity), homologues are found in Thermobifida fusca [Accession No. ZP_00057880; 59\% protein identity to GIcP of S. coelicolor A3(2)] and in other (non-sporulating) actinomycetes such as bifidobacteria, corynebacteria and mycobacteria. We have evidence that the glcP homologue of Bifidobacterium longum is a specific glucose permease (our unpublished results). For the others, experimental investigation remains to be awaited to answer the question whether glucose uptake via GlcP is widely spread among this class of bacteria.

In conclusion, the identification of GlcP as the main glucose transporter in S. coelicolor A3(2) sheds new light on the early stages of glucose-mediated processes in this important model organism. We are currently studying these relationships between glucose internalization via GlcP and glucose signalling concerning carbon regulation, antibiotic production and development.

\section{Experimental procedures}

Bacterial strains, plasmids, oligonucleotides and culture conditions

All strains and plasmids described in this article are presented in Table 1. The oligonucleotides used in this study are described in Supplementary material (Table S1). E. coli $\mathrm{DH} 5 \alpha$ served as host for standard cloning procedures. The glucose transport-deficient E. coli strains LR2-175 and LM1 were used for heterologous complementation experiments (Lengeler et al., 1981; Aulkemeyer et al., 1991). E. coli ET12567(pUZ8002) was used for plasmid transfer via conjugation. S. coelicolor A3(2) strains M145 (SCP1- SCP2 ${ }^{-}$) and M512 (M145 $\Delta$ redD $\Delta$ actll-ORFIV), and S. lividans TK24 were obtained from the John Innes Centre strain collection. M512 was used as host for promoter probing experiments. pSU2718 (Martinez et al., 1988) and pBluescript II SK(+) were used for routine cloning experiments. pSET151, which contains a pUC origin of replication but is non-replicative in streptomycetes, was used for gene disruption experiments. S. coelicolor $\mathrm{A} 3(2)$ and $S$. lividans strains were grown in tryptic soy broth without dextran (TSB; Difco) for isolation of 
Table 1. Strains and plasmids used in this study.

\begin{tabular}{|c|c|c|}
\hline Strains/plasmids & Genotype/description & Reference \\
\hline \multicolumn{3}{|l|}{$\begin{array}{l}\text { Strains } \\
\text { S. coelicolor A3(2) }\end{array}$} \\
\hline $\begin{array}{l}\text { S. coelicolor A3(2) } \\
\text { M145 }\end{array}$ & $\mathrm{SCP} 1^{-}, \mathrm{SCP}^{-}$, prototroph & Hopwood et al. (1985) \\
\hline M512 & M145 $\Delta$ redD $\triangle$ actll-ORF4 & Floriano and Bibb (1996) \\
\hline BAP18 & M145 $\Delta g l c P 2:: a p r$ & This work \\
\hline BAP19 & M145 $\Delta / c P 1:: h y g$ & This work \\
\hline BAP20 & M145 $\Delta g / c P 1:: a p r \Delta g / c P 2:: h y g$ & This work \\
\hline \multicolumn{3}{|l|}{ S. lividans } \\
\hline TK24 & Wild type & Hopwood \\
\hline \multicolumn{3}{|l|}{ E. coli } \\
\hline $\mathrm{DH} 5 \alpha$ & supE44 lacU109 ( $\phi 80 l a c Z \Delta M 15 M)$ hsdR17 recA1 endA1 gqrA96 thi-1 relA1 & Ausubel et al. (1990) \\
\hline ET12567 & $\begin{array}{l}\mathrm{F}^{-} \text {dam13::Tn9 dcm6 hsdM hsd RrecF143 zjj201::Tn10 galK2 galT22 ara-14 lacY1 xyl-5 } \\
\text { leuB6 thi-1 tonA31 rpsL136 hisG4 tsx-78 mtl-1 glnV44 }\end{array}$ & MacNeil et al. (1992) \\
\hline LM1 & tonA, galT, nagE, manAl, kbats, rpll, xyl, metB, thi, his, mgla-C, argG, crr & Lengeler et al. (1981) \\
\hline LR2-175 & galP manA, nagE, glcA, fruA, mak ${ }^{\circ}$ & Aulkemeyer et al. (1991) \\
\hline \multicolumn{3}{|l|}{ Plasmids } \\
\hline pUZ8002 & oriT kan, conjugation helper plasmid & Sia et al. (1996) \\
\hline pBluescript II SK+ & bla, high-copy cloning vector & Stratagene \\
\hline pSU2718 & cat, low-copy cloning vector & Martinez et al. (1988) \\
\hline pFT76 & pSU2718 with glcP2 S. coelicolor A3(2) & This work \\
\hline pHPShyg & hyg, Hyg resistance cassette & M.-J. Virolle (unpubl.) \\
\hline pHLW1 & aacC4, Apr resistance cassette & Parche et al. (1999) \\
\hline pSET151 & oriT RK2 bla tsr & Hillemann et al. (1991) \\
\hline pFT202 & pBluescript II SK+ with glcP1 downstream region & This work \\
\hline pFT204 & pSET151 with $g / c P 1$ upstream region & This work \\
\hline pFT205 & pSET151 with glcP2 upstream region & This work \\
\hline pFT206 & pBluescript II SK+ with glcP2 downstream region & This work \\
\hline pFT207 & pFT204 with $g / c P 1$ downstream region & This work \\
\hline pFT209 & pFT206 derivative, apr & This work \\
\hline pFT211 & pFT207 $\Delta g / c P 1:: h y g$ & This work \\
\hline pFT212 & pFT205 $\triangle$ glcP2::aacC4 & This work \\
\hline plJ2587 & Promoter probe vector containing promoterless redD gene & van Wezel et al. (2000) \\
\hline plJ2587-glcP1p & plJ2587 with $g / c P 1$ promoter region $(-192 /+49$ relative to the start of $g / c P 1)$ & This work \\
\hline plJ2587-glcP2p & plJ2587 with $g l c P 2$ promoter region $(-192 /+49$ relative to the start of $g / c P 2)$ & This work \\
\hline
\end{tabular}

chromosomal DNA, and in mineral medium supplemented with $0.1-0.2 \%(\mathrm{w} / \mathrm{v})$ casamino acids and $50 \mathrm{mM}$ carbon source for growth curves and transport experiments (Kieser et al., 2000; Mahr et al., 2000; Nothaft et al., 2003b). E. coli strains were grown in Luria-Bertani (LB) broth at $37^{\circ} \mathrm{C}$. The antibiotics ampicillin (100 $\left.\mathrm{mg} \mathrm{l}^{-1}\right)$, apramycin $\left(25 \mathrm{mg} \mathrm{l}^{-1}\right)$, chloramphenicol (25 $\left.\mathrm{mg} \mathrm{l}^{-1}\right)$, hygromycin $\left(100 \mathrm{mg} \mathrm{l}^{-1}\right.$ for $S$. coelicolor, $200 \mathrm{mg} \mathrm{I}^{-1}$ for $E$. coll), kanamycin $\left(60 \mathrm{mg} \mathrm{l}^{-1}\right)$ or thiostrepton $\left(25 \mathrm{mg} \mathrm{l}^{-1}\right)$ were added where appropriate.

\section{Cloning of glcP genes}

Chromosomal DNA of S. coelicolor A3(2) M145 was isolated as described (Parche et al., 1999). A 1487 bp DNA fragment comprising the glcP-coding region of $S$. coelicolor A3(2) was amplified from chromosomal DNA by PCR with Pfu DNA polymerase using oligonucleotides GluT1 and GluT2. GluT1 was designed such as to provide stop codons in all three reading frames preceding the ribosomal binding site. The PCR fragment was digested with Pstl and cloned into pSU2718 digested with Smal and Pstl in transcriptional fusion to the plasmid-borne lacZ promoter. The insertion was confirmed by DNA sequencing on an ABI PRISM 310 Genetic Analyzer (Perkin-Elmer) and the constructed plasmid was designated pFT76 $\left(g / c P^{+}\right)$.

\section{Glucose transport assays}

Transport assays for $S$. coelicolor A3(2) strains were performed as described previously (Nothaft et al., 2003b). E. coli strains were grown in LB supplemented with chloramphenicol $\left(50 \mu \mathrm{g} \mathrm{ml}^{-1}\right)$ to an $\mathrm{OD}_{600}$ of $1.2-2.0$. Cells were harvested by centrifugation, washed twice in transport buffer (50 mM Tris- $\mathrm{HCl}, \mathrm{pH} 7.5,50 \mathrm{mM} \mathrm{NaCl}, 10 \mathrm{mM} \mathrm{KCl}$ ) and adjusted in the same buffer to an $\mathrm{OD}_{600}$ of 1.0. Cells were kept on ice and pre-incubated for $5 \mathrm{~min}$ at $37^{\circ} \mathrm{C}$ for the uptake assay. Uptake was initiated by addition of [U$\mathrm{C}^{14}$-glucose at a final concentration of 20 or $100 \mu \mathrm{M}$ $\left(5 \mathrm{mCi} \mathrm{mmol}^{-1}\right)$. Samples $(1 \mathrm{ml})$ were taken at different time points (10 s to $10 \mathrm{~min}$ ) and treated as described (Nothaft et al., 2003b). The initial velocity of glucose incorporation was linear for at least $60 \mathrm{~s} . K_{\mathrm{m}}$ and $V_{\max }$ were calculated from samples withdrawn after $10 \mathrm{~s}$, using glucose concentrations ranging from $10 \mu \mathrm{M}$ to $1 \mathrm{mM}$. Potential transport inhibitors (CCCP, $50 \mu \mathrm{M}$; DNP, $1 \mathrm{mM}$; DCCD, $0.5 \mathrm{mM}$; all purchased from Sigma) or non-radioactive sugars (10 mM) for the test of substrate specificity were added 1 min before addition of radio-labelled glucose $(100 \mu \mathrm{M})$. Samples were collected after $1 \mathrm{~min}$. It should be noted that the absolute transport activity of $S$. coelicolor $A 3(2)$ strains varied from experiment to experiment because of variation in the dispersity of the mycelia. We found that data between strains 
were only comparable when grown in parallel in the same batch of medium.

\section{Construction of glcP1/glcP2 mutants}

The deletion vectors pFT211 for glcP1 and pFT212 for glcP2 were constructed as described below. Amplifications were performed with S. coelicolor A3(2) M145 chromosomal DNA. All PCR products were checked by DNA sequencing.

(i) Construction of pFT211 ( $\Delta g l c P 1)$ : a 924 bp fragment containing the $g / c P 1$ downstream region was amplified with oligonucleotides GlcP1-1 and GlcP1-2. This PCR product was inserted as a BamHI-EcoRI fragment into pBluescript II $\mathrm{SK}+$, yielding pFT202. A $1007 \mathrm{bp}$ fragment containing the glcP1 upstream region was amplified with primers GlcP1-3 and GlcP1-4, and was cloned as a BamHI-Hindlll fragment into pSET151, giving pFT204. The glcP1 downstream region was further cloned as a BamHI-EcoRI fragment from pFT202 into pFT204, yielding pFT207. The hygromycin resistance cassette (hyg) was obtained from pHPShyg (M.-J. Virolle, unpubl.) and cloned as a BamHI fragment in the same transcriptional orientation as glcP1 into pFT207, yielding pFT211.

(ii) Construction of pFT212 ( $\Delta g / c P 2)$ : a 986 bp fragment containing the $g / c P 2$ downstream region was amplified using oligonucleotides GlcP2-1 and GlcP2-2, and inserted as a BamHI-EcoRI fragment into pBluescript II SK+, yielding pFT206. A 988 bp fragment containing the glcP2 upstream region was obtained by PCR with primers GlcP2-3 and GlcP2-4, and cloned as a Hindll-Xbal fragment into pSET151, giving plasmid pFT205. The apramycin resistance cassette (aacC4) was obtained from pHLW1 (Parche et al., 1999) and cloned in the same orientation as glcP2 as a BamHI-Xbal fragment into pFT206, yielding pFT209. The insert of pFT209 ( $g / c P 2$ downstream region preceded by aacC4) was then transferred as an Xbal-EcoRl fragment into pFT205, giving the final glcP2 deletion vector pFT212.

Construction of the null mutants was achieved by conjugational transfer from ET12567(pUZ8002) harbouring pFT211 ( $\Delta$ glcP1::hyg) or pFT212 ( $\Delta$ glcP2::aacC4), respectively, to $S$. coelicolor A(3)2 M145 (Kieser et al., 2000). Ex-conjugants with the phenotype $\mathrm{Hyg}^{\mathrm{r}} \mathrm{Tsr}^{\mathrm{s}}$ or $\mathrm{Apr}^{\mathrm{r}} \mathrm{Tsr}^{\mathrm{s}}$ were clonally isolated. Sensitivity to thiostrepton $\left(\mathrm{Tsr}^{s}\right)$ was used as marker for loss of the non-replicating gene disruption vector, while resistance to hygromycin $\left(\mathrm{Hyg}^{\mathrm{r}}\right)$ or apramycin $\left(\mathrm{Apr}^{\mathrm{r}}\right)$ was a marker for the desired recombination event. The expected gene replacements were verified by PCRs that revealed the presence of the hygromycin and apramycin resistance cassettes (hyg and aacC4) and the correct chromosomal position, using oligonucleotides that hybridized in the antibiotic resistance gene and on the chromosome just outside the recombination area. One mutant ex-conjugant was designated BAP17 ( $\Delta g / c P 1:: h y g)$ and one BAP18 ( $\Delta g / c P 2:: a a c C 4)$. The same procedure was used to generate the double recombinant BAP20 ( $\Delta g / c P 1:: h y g \Delta g l c P 2:: a a c C 4)$ via conjugation of pFT212 into BAP17. The deleted regions comprised nt positions 34-1384 of $g / c P 1$ and nt 29-1399 of glcP2.

\section{RT-PCR analyses}

RNA was prepared from cultures of $S$. coelicolor M145 grown for $40 \mathrm{~h}$ in $50 \mathrm{ml}$ of mineral medium supplemented with $0.1 \%$ (w/v) casamino acids and with $50 \mathrm{mM}$ glycerol or $50 \mathrm{mM}$ glucose (Nothaft et al., 2003b). RT-PCR analyses were carried out with the one-step RT-PCR Kit (Qiagen) as described previously (Bertram et al., 2004). The quality of the RNA preparations was controlled by the presence of equal amounts of constitutively expressed 16S rRNA with oligonucleotides 16SRT-for and 16SRT-rev. RT-PCR experiments without prior reverse transcription were performed to assure exclusion of DNA contamination. For quantitative analysis, samples were taken at three-cycle intervals between cycles 18-35 to compare non-saturated PCR product formation. Data were verified in three independent experiments.

\section{Streptomyces growth curves}

Normal growth curves of $S$. coelicolor A3(2) M145 and its $g / c P 1, g / c P 2$ and $g / c P 1 g / c P 2$ mutant derivatives were performed in $500 \mathrm{ml}$ of NMMP cultures containing $50 \mathrm{mM}$ glucose as the sole carbon source, and reduced concentration of casamino acids $(0.2 \%)$. The strains were pre-grown for $16 \mathrm{~h}$ in NMMP + $50 \mathrm{mM}$ mannitol; the mycelium was spun down, washed in NMMP without carbon source, and used to inoculate the main culture at a starting $\mathrm{OD}_{550}$ of 0.1 . Cultures were grown at $30^{\circ} \mathrm{C}$, under constant shaking (300 r.p.m.), and biomass accumulation was monitored by measuring the $\mathrm{OD}_{550}$. In parallel, disappearance of glucose from the medium was monitored qualitatively using a glucose assay kit (Sigma).

\section{Promoter probing experiments}

For general assessment of promoter activity, we used the redD reporter system (van Wezel et al., 2000). The redD gene encodes the activator of the pathway for the redpigmented tripyrrole undecylprodigiosine (Red). Promoter activity of DNA fragments cloned upstream of redD in the SCP2*-based plasmid plJ2587 (around five copies per chromosome) results in accumulation of RedD and hence in rapid activation of Red biosynthesis in the indicator strain, S. coelicolor A3(2) M512; in the absence of promoter activity M512 is essentially unpigmented because of the absence of redD as well as actll-ORFIV, the activator for the act biosynthesis cluster. For assessing the activity of the $\mathrm{glcP} 1$ and $\mathrm{glcP} 2$ promoters, we analysed the $-192 /+49$ regions (relative to the start of the respective genes). The glcP1 promoter fragment was amplified by PCR using oligonucleotides GlcP11E and GlcP11B, and the glcP2 promoter region was amplified using oligonucleotides GlcP21E and GlcP11B. In both cases, the oligonucleotides added an $\mathrm{EcoRI}$ and a $\mathrm{BamHI}$ site to the upstream and downstream end of the fragments, respectively, allowing insertion of the fragment in the correct orientation in front of the promoterless redD gene. The constructs were named plJ2587-glcP1p and plJ2587-glcP2p for analysis of the $g / c P 1$ and $g / c P 2$ promoters respectively. Red production by the transformants on R2YE was monitored at approximately $12 \mathrm{~h}$ intervals during 6 days.

\section{Nuclease S1 mapping}

Total RNA was purified from liquid-grown NMMP cultures as 
described (Kieser et al., 2000), except that DNase I treatment was used in addition to salt precipitation to fully eliminate DNA from the nucleic acid preparations. Appropriate primers (below) were labelled at their $5^{\prime}$ ends with $\left[\gamma^{32} \mathrm{P}\right]$-ATP with T4 polynucleotide kinase before DNA probes were produced by PCR. High-resolution S1 nuclease mapping was carried out as described previously (Kieser et al., 2000). For each RNA protection assay, excess of probe was hybridized to $30 \mu \mathrm{g}$ of RNA. Protected fragments were analysed on denaturing $6 \%$ polyacrylamide gels, alongside a DNA sequencing ladder. Probes GP1 and GP2 were produced by PCR and used for mapping $g / c P 1$ and $g / c P 2$ transcripts respectively. Both correspond to the $-192 /+49$ region. Probe GP1 was produced using oligonucleotides GlcP11E and GlcP-S1, and probe GP2 was produced using oligonucleotides GlcP21E and GlcP-S1. For the glcP induction experiments, mycelium from an exponentially growing TSB culture of $S$. coelicolor A3(2) M145 was harvested at an $\mathrm{OD}_{550}$ of 0.7 and resuspended in NMMP (but without casamino acids) with $50 \mathrm{mM}$ glucose or $50 \mathrm{mM}$ mannitol. RNA was isolated after 0, 15, 30, 60, 120 and $240 \mathrm{~min}$ and subjected to nuclease S1 mapping.

\section{Computer analyses}

The LaserGene workstation software (DNASTAR) was used to process DNA and protein sequence data. The glcP genes were identified by BLAST analysis of the $S$. coelicolor A3(2) genome (http://www.sanger.ac.uk/Projects/ S_coelicolor). Protein databank searches were performed with the BLAST server of the National Center for Biotechnology Information at the National Institutes of Health Bethesda, MD, USA (http://www.ncbi.nlm.nih.gov). Hydrophobicity analysis was conducted using the TMPred algorithm (http://www.ch.embnet.org).

\section{Acknowledgements}

We thank Marie-Joëlle Virolle and Jan Kormanec for very fruitful discussions and Knut Jahreis for gift of $E$. coli strains. This work was funded by Grants SFB473, GK40 (to M.K. and K.M.), and GK805 (to E.F.P.S.) of the Deutsche Forschungsgemeinschaft, and by a grant from the Royal Netherlands Academy for Arts and Sciences (KNAW) to G.P.v.W.

\section{Supplementary material}

The following material is available from http://www.blackwellpublishing.com/products/journals/ suppmat $/ \mathrm{mmi} / \mathrm{mmi} 4413 / \mathrm{mmi} 4413 . \mathrm{sm} \cdot \mathrm{htm}$

Fig. S1. In vivo promoter probe analysis of $g / c P 1$ and $g / c P 2$ and the sequence of the glcP1 promoter region.

Fig. S2. Topology model of GlcP.

Table S1. List of oligonucleotides.

\section{References}

Angell, S., Lewis, C.G., Buttner, M.J., and Bibb, M.J. (1994) Glucose repression in Streptomyces coelicolor A3(2): a likely regulatory role for glucose kinase. Mol Gen Genet 244: 135-143.
Aulkemeyer, P., Ebner, R., Heilenmann, G., Jahreis, K., Schmid, K., Wrieden, S., and Lengeler, J.W. (1991) Molecular analysis of two fructokinases involved in sucrose metabolism of enteric bacteria. Mol Microbiol 5: 29132922.

Ausubel, F.A., Brent, R., Kingston, R.E., Moore, D.D., Seidmann, J.G., Smith, J.A., and Struhl, K. (1990) Current Protocols in Molecular Biology. New York: Greene Publishing and Wiley-Interscience.

Baltz, R.H. (1998) Genetic manipulation of antibioticproducing Streptomyces. Trends Microbiol 6: 76-83.

Bentley, S.D., Chater, K.F., Cerdeno-Tarraga, A.M., Challis, G.L., Thomson, N.R., James, K.D., et al. (2002) Complete genome sequence of the model actinomycete Streptomyces coelicolor A3(2). Nature 417: 141-147.

Bertram, R., Schlicht, M., Mahr, K., Nothaft, H., Saier, M.H., Jr, and Titgemeyer, F. (2004) In silico and transcriptional analysis of carbohydrate uptake systems of Streptomyces coelicolor A3(2). J Bacteriol 186: 1362-1373.

Bibb, M. (1996) 1995 Colworth Prize Lecture. The regulation of antibiotic production in Streptomyces coelicolor A3(2). Microbiology 142: 1335-1344.

Brückner, R., and Titgemeyer, F. (2002) Carbon catabolite repression in bacteria: choice of the carbon source and autoregulatory limitation of sugar utilization. FEMS Microbiol Lett 209: 141-148.

Chater, K.F. (1998) Taking a genetic scalpel to the Streptomyces colony. Microbiology 144: 1465-1478.

Escalante, L., Ramos, I., Imriskova, I., Langley, E., and Sanchez, S. (1999) Glucose repression of anthracycline formation in Streptomyces peucetius var. caesius. Appl Microbiol Biotechnol 52: 572-578.

Floriano, B., and Bibb, M. (1996) afsR is a pleiotropic but conditionally required regulatory gene for antibiotic production in Streptomyces coelicolor A3(2). Mol Microbiol 21: 385-396.

Gagnat, J., Chouayekh, H., Gerbaud, C., Francou, F., and Virolle, M.J. (1999) Disruption of sblA in Streptomyces lividans permits expression of a heterologous alphaamylase gene in the presence of glucose. Microbiology 145: 2303-2312.

Garcia-Dominguez, M., Martin, J.F., and Liras, P. (1989) Characterization of sugar uptake in wild-type Streptomyces clavuligerus, which is impaired in glucose uptake, and in a glucose-utilizing mutant. $J$ Bacteriol 171: 68086814.

Hillemann, D., Pühler, A., and Wohlleben, W. (1991) Gene disruption and gene replacement in Streptomyces via single stranded DNA transformation of integration vectors. Nucleic Acids Res 19: 727-731.

Hodgson, D.A. (1982) Glucose repression of carbon source uptake and metabolism in Streptomyces coelicolor $\mathrm{A} 3(2)$ and its perturbation in mutants resistant to 2deoxyglucose. J Gen Microbiol 128: 2417-2430.

Hodgson, D.A. (2000) Primary metabolism and its control in streptomycetes: a most unusual group of bacteria. $A d v$ Microb Physiol 42: 47-238.

Hopwood, D.A., Bibb, M.J., Chater, K.F., Kieser, T., Bruton, C.J., Kieser, H.M., et al. (1985) Genetic Manipulation of Streptomyces. A Laboratory Manual. Norwich, UK: John Innes Foundation. 
Hurtubise, Y., Shareck, F., Kluepfel, D., and Morosoli, R. (1995) A cellulase/xylanase-negative mutant of Streptomyces lividans 1326 defective in cellobiose and xylobiose uptake is mutated in a gene encoding a protein homologous to ATP-binding proteins. Mol Microbiol 17: 367-377.

Ikeda, H., Ishikawa, J., Hanamoto, A., Shinose, M., Kikuchi, H., Shiba, T., et al. (2003) Complete genome sequence and comparative analysis of the industrial microorganism Streptomyces avermitilis. Nat Biotechnol 21: 526-531.

Kieser, T., Bibb, M.J., Buttner, M.J., Chater, K.F., and Hopwood, D.A. (2000) Practical Streptomyce Genetics. Norwich, UK: The John Innes Foundation.

Kim, E.S., Hong, H.J., Choi, C.Y., and Cohen, S.N. (2001) Modulation of actinorhodin biosynthesis in Streptomyces lividans by glucose repression of afsR2 gene transcription. J Bacteriol 183: 2198-2203.

Kwakman, J.H., and Postma, P.W. (1994) Glucose kinase has a regulatory role in carbon catabolite repression in Streptomyces coelicolor. J Bacteriol 176: 2694-2698.

Lengeler, J., Auburger, A.M., Mayer, R., and Pecher, A. (1981) The phosphoenolpyruvate-dependent carbohydrate: phosphotransferase system enzymes II as chemoreceptors in chemotaxis of Escherichia coli K 12. Mol Gen Genet 183: 163-170.

MacNeil, D.J., Gewain, K.M., Ruby, C.L., Dezeny, G., Gibbons, P.H., and MacNeil, T. (1992) Analysis of Streptomyces avermitilis genes required for avermectin biosynthesis utilizing a novel integration vector. Gene 111: 61-68.

Mahr, K., van Wezel, G.P., Svensson, C., Krengel, U., Bibb, M.J., and Titgemeyer, F. (2000) Glucose kinase of Streptomyces coelicolor A3(2): large-scale purification and biochemical analysis. Antonie Van Leeuwenhoek 78: 253261.

Martinez, E., Bartolome, B., and de la Cruz, F. (1988) pACYC184-derived cloning vectors containing the multiple cloning site and lacZ alpha reporter gene of $\mathrm{pUC8/9}$ and pUC18/19 plasmids. Gene 68: 159-162.

Nothaft, H., Dresel, D., Willimek, A., Mahr, K., Niederweis, M., and Titgemeyer, F. (2003a) The PTS of Streptomyces coelicolor is biased for $\mathrm{N}$-acetylglucosamine metabolism. J Bacteriol 185: 7019-7023.

Nothaft, H., Parche, S., Kamionka, A., and Titgemeyer, F. (2003b) In vivo analysis of HPr reveals a fructose-specific phosphotransferase system that confers high-affinity uptake in Streptomyces coelicolor. J Bacteriol 185: 929937.

Pao, S.S., Paulsen, I.T., and Saier, M.H., Jr (1998) Major facilitator superfamily. Microbiol Mol Biol Rev 62: 1-34.

Parche, S., Schmid, R., and Titgemeyer, F. (1999) The phosphotransferase system (PTS) of Streptomyces coelicolor. identification and biochemical analysis of a histidine phosphocarrier protein HPr encoded by the gene ptsH. Eur J Biochem 265: 308-317.

Parche, S., Nothaft, H., Kamionka, A., and Titgemeyer, F. (2000) Sugar uptake and utilisation in Streptomyces coelicolor. a PTS view to the genome. Antonie Van Leeuwenhoek 78: 243-251.

Parker, C., Barnell, W.O., Snoep, J.L., Ingram, L.O., and Conway, T. (1995) Characterization of the Zymomonas mobilis glucose facilitator gene product $(g / f)$ in recombinant Escherichia coli: examination of transport mechanism, kinetics and the role of glucokinase in glucose transport. Mol Microbiol 15: 795-802.

Pope, M.K., Green, B.D., and Westpheling, J. (1996) The bld mutants of Streptomyces coelicolor are defective in the regulation of carbon utilization, morphogenesis and cellcell signalling. Mol Microbiol 19: 747-756.

Postma, P.W., Lengeler, J.W., and Jacobson, G.R. (1993) Phosphoenolpyruvate: carbohydrate phosphotransferase systems of bacteria. Microbiol Rev 57: 543-594.

Sabater, B., and Asensio, C. (1973) Transport of hexoses in Streptomyces violaceoruber. Eur J Biochem 39: 201-205.

Sarker, R.I., Okabe, Y., Tsuda, M., and Tsuchiya, T. (1996) Sequence of a Na+/glucose symporter gene and its flanking regions of Vibrio parahaemolyticus. Biochim Biophys Acta 1281: 1-4.

Schlösser, A. (2000) MsiK-dependent trehalose uptake in Streptomyces reticuli. FEMS Microbiol Lett 184: 187-192.

Schlösser, A., and Schrempf, H. (1996) A lipid-anchored binding protein is a component of an ATP-dependent cellobiose/cellotriose-transport system from the cellulose degrader Streptomyces reticuli. Eur J Biochem 242: 332328.

Schlösser, A., Kampers, T., and Schrempf, H. (1997) The Streptomyces ATP-binding component MsiK assists in cellobiose and maltose transport. J Bacteriol 179: 20922095.

Seo, J.W., Ohnishi, Y., Hirata, A., and Horinouchi, S. (2002) ATP-binding cassette transport system involved in regulation of morphological differentiation in response to glucose in Streptomyces griseus. J Bacteriol 184: 91-103.

Sia, E.A., Kuehner, D.M., and Figurski, D.H. (1996) Mechanism of retrotransfer in conjugation: prior transfer of the conjugative plasmid is required. J Bacteriol 178: 14571464.

Strohl, W.R. (1992) Compilation and analysis of DNA sequences associated with apparent streptomycete promoters. Nucleic Acids Res 20: 961-974.

Titgemeyer, F., Walkenhorst, J., Reizer, J., Stuiver, M.H., Cui, X., and Saier, M.H., Jr (1995) Identification and characterization of phosphoenolpyruvate: fructose phosphotransferase systems in three Streptomyces species. Microbiology 141: 51-58.

Ueda, K., Endo, K., Takano, H., Nishimoto, M., Kido, Y., Tomaru, Y., et al. (2000) Carbon-source-dependent transcriptional control involved in the initiation of cellular differentiation in Streptomyces griseus. Antonie Van Leeuwenhoek 78: 263-268.

Wang, M.Y., Tsai, M.Y., and Wang, C. (1994) Identification of chicken liver glucose transporter. Arch Biochem Biophys 310: 172-179.

Wang, F., Xiao, X., Saito, A., and Schrempf, H. (2002) Streptomyces olivaceoviridis possesses a phosphotransferase system that mediates specific, phosphoenolpyruvatedependent uptake of $\mathrm{N}$-acetylglucosamine. Mol Genet Genomics 268: 344-351.

Weisser, P., Krämer, R., Sahm, H., and Sprenger, G.A. (1995) Functional expression of the glucose transporter of Zymomonas mobilis leads to restoration of glucose and fructose uptake in Escherichia coli mutants and provides evidence for its facilitator action. J Bacteriol 177: 33513354. 
van Wezel, G.P., White, J., Young, P., Postma, P.W., and Bibb, M.J. (1997) Substrate induction and glucose repression of maltose utilization by Streptomyces coelicolor A3(2) is controlled by malR, a member of the lacl-galR family of regulatory genes. Mol Microbiol 23: 537-549.

van Wezel, G.P., White, J., Hoogvliet, G., and Bibb, M.J. (2000) Application of redD, the transcriptional activator gene of the undecylprodigiosin biosynthetic pathway, as a reporter for transcriptional activity in Streptomyces coelicolor A3(2) and Streptomyces lividans. J Mol Microbiol Biotechnol 2: 551-556.

Zhang, C.C., Durand, M.C., Jeanjean, R., and Joset, F. (1989) Molecular and genetical analysis of the fructoseglucose transport system in the cyanobacterium Synechocystis PCC6803. Mol Microbiol 3: 1221-1229. 